\title{
ANOMALOUS RF MAGNETORESISTANCE IN COPPER AT $4^{\circ} \mathrm{K}$
}

H. J. Halama, A. G. Prodell, J. T. Rogers, S. De Panfilis, A. C. Melissinos, B. E. Moskowitz

Y. K. Semertzidis, W. U. Wuenscin, W. B. Fowler, and F. A. Nezrick

March 1988

\author{
INFORMAL REPORT \\ Accelerator Development Department \\ BROOKHAVEN NATIONAL LABORATORY \\ ASSOCIATED UNIVERSITIES, INC. \\ Under Contract No. DEAC0276CH00016 \\ with the \\ UNITED STATES DEPARTMENT OF ENERGY
}

\section{DISCLAIMER}

This report was prepared as an account of work sponsored by an agency of the Unitod States Government. Neither the United States Gowernment nor any agency thereor, nor any of their employees, makes any warranty, express or implied, or assumes any legal liability or responsibility for the accuracy, completeness, or usefulness of any information, apperatus, product, or process disclosed, or represents that its use woukd not infringe privately owned rights Reference herein to any specific commercial product, process, or service by trade name, trademark, manufacturer, or otherwise does not necessarily constitute or imply its endorsement, recommendation, or favoring by the United States Government or any agency thereof. The views and opinions of authors expressed herein do not necessarily state or reflect those of the United States Government or any agency thereof.

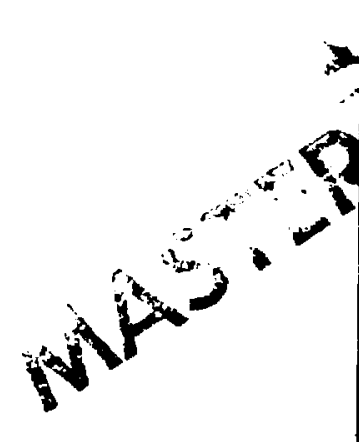




\title{
Anomalous IF Magnetorealatance in Copper et $4^{\circ} \mathrm{K}$
}

\author{
J. T. Rogeze, S. De Panfille, A. C. Hellasinos, \\ B. E. Moskowitz, Y. R. Semerezidis, and W. O. Wuensch \\ Department of Physics Astronomy, University of Rochester \\ Rochester, NY 14627 \\ H. J. Helama and A. G. Prodell \\ Brookhaven Nat1onal Laboratory, Upton, NI 11973 \\ H. B. Fowler and F. A. Nezrick \\ Fert: National Accelerator Laboratory, Batav1a, IL 60510
}


Abstract

We have measured the effect of a magnetic field on the surface resistance of polycrystalline $\mathrm{Cu}$ at $\mathrm{f}=1.2 \mathrm{Gg}$ and at $4.4^{\circ} \mathrm{K}_{\mathrm{f}}$ under these conditions the

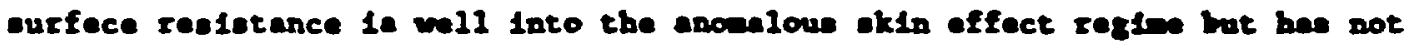
reached lIte linting value. We find that the transverse and longitudinal agnetorealetance are an order of angnitude smaller than, the DC agrotoresistance and depend quadratically on the field. At low fields we observe a decrease in surface resistance with increasing field which can be interpreted as a size effect of the RF surface current.

PACS numbers: $72.90+y, 73.25+1,75.80+q$ 
The resiotivity of actal is the oum of a temperature-dependent term ariaing frow electron-phonon acattering and a temerature-independent term due to Imurities and other lattice defects. At low teperatures the resietivity of $\mathrm{Cu}$ 10 domfnated by these defects. Their contribution can be characterized

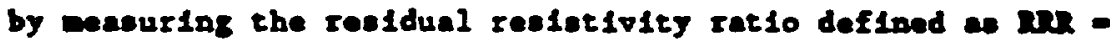
$p\left(T-273^{\circ} \mathrm{X}\right) / p\left(T-4.2^{\circ} \mathrm{K}\right)$. Albo, the rosietfrity of metele generally increases in - angetic fleld. Longltudinal angetoresistance, where the current is perellel to the megnetic fleld I tends to be meller by about an order of magnitude then transverse engnetoresisance, wth the current perpendicular to B. At high frequencles, the currents in a conductor are confined to a thin surface layer, which possesses a surface resistance. In the present Investigation we measured the surface resistance as anction of temperature and of magnetic fleld in a microweve cavity manufactured from Hitach ofE hard drawn copper ${ }^{2}$ of nominal purity 99.9962.

The apparatus used for these measurements 1. part of a detector eearching for the existence of galactic axions in the $1-3 \mathrm{GHz}$ range. ${ }^{2}$ The interest in magnetoreststance arises in connection with the SSC design studies. ${ }^{3}$ The SSC beam plpe is Cu-plated and it is desirable to know the surface resistance o: Cu at high frequencles and at low temperatures in transuerse magnetic fleld. These measurements show that even for a 5.8 I magnetic fleld the surface resistance changes by only few percent.

Surface Resistance: The ourface reststance $R$, was deduced from the measured electrical quality factor $Q_{0}$ of a microwave cavity. The cavity was contructed as a cyllnder of $7.94 \mathrm{~cm}$ Inner radius and $40.48 \mathrm{~cm}$ length. The cavity surface was honed to $3 \mathrm{pm}$ flatness and electropolished with a solution of $75 \%$ phosphor1c ac1d (852 ACS) and 252 Electro-Glo 200 concentrate." This creatment produced a visually opecularly reflecting surface. 
The cavity $Q$ is defined by $Q=U(W / P)$ where $W$ is the etored energy, $P$ the power diesipated In the cavity walle, and the angular frequency. The diselpated power 1a proportionel to $\mathrm{K}_{\text {, and }}$ a the squere of the tangential coponent of the oec1llating agpet1c fleld, $z_{t}$ integrated over the cavity

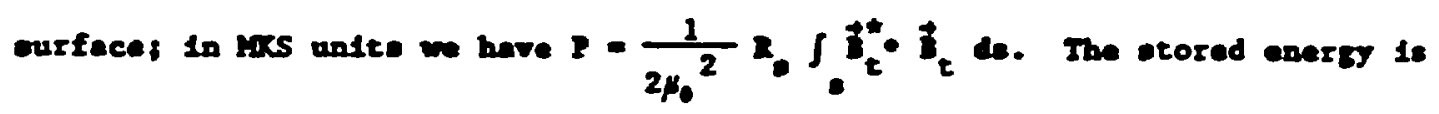
$U=\frac{1}{2} \epsilon_{0} \int_{v} E^{*} \cdot E^{+} d v$, the Integration being over the cavity volume. Thus $1 t$ 1s possible to express

$$
\text { Q. }-\mathbf{A} / \mathbf{R} \text {. }
$$

where A 1s a calculable constant dependent on the cavity geometry and the mode under consideration. 5

A swept frequency microwave generator fed power to the cavity through a very weakly coupled loop; the tranamitted power vas plcked up by weakly coupled loop and displayed on a network analyzer (Fig. 1). The full vidth of the cavity resonance at half maximum, $\Delta f$, could be measured to an accuracy of 37, yielding the quality factor $Q_{0}=f / \Delta f$. The cavity was allowed to fill with liquid helium, with no measurable effect on $Q_{0}$.

The results obtained for $R_{s}$ as a function of temperature for two different cavieles for the $\mathrm{TH}_{010}$ mode $\left(f=1.249 \mathrm{GHz}\right.$ ) and $\mathrm{TE}_{114}$ mode $(f=2.426 \mathrm{GHz}$ ) normalized for an $w^{2 / 3}$ frequency dependence to $f=1.249$ ere shown $\ln \mathrm{F}$ Ig. 2 and are in excellent agreement. We note that $R_{\text {s }}$ changes only by a factor of 4 from room to liguld hellum temperature. The saturation has two causes: lattice defects and the anomalous skin effect.

Anomeious Skin Effect: At room temperature the eurface resistance can be related to the realstivity of the aterial by the classical okin depth expression 6

$$
R_{s}=\rho / \delta \quad \delta=\sqrt{2 \rho / \mu_{0} \omega}
$$


Oelng $p(273)=1.55 \times 10^{-8} \mathrm{a}$ for $\mathrm{Cu}$ we Elnd that at $\mathrm{f}=1.249 \mathrm{~GB}, \mathrm{R}_{5}(273)=$ $8.5 \times 10^{-3} \mathrm{D}$, in good agreement with the data.

As the temperature decreases so does the resietiolty, and for oufficlently $100 p$ the eeen free path 2 of the conduction electrons becone longer then the claselcal okin depth. In thls case the claselcal asermption of diffusive electron flow, and therefore Iq. (2), becones Invalld, and In this anomalous skin effect $11 \mathrm{~m} 1 \mathrm{t}^{7}$ the aurface resiatance approaches a 1 indting value $R_{0}$. The departure of the resistivity from the classical model can be characterised by the dimensionless parameter

$$
a=\frac{3}{4} \mu_{0} \omega(\rho \ell)^{2} p^{-3}
$$

For $a \leqslant 0.02$, Eg. (2) 1s val1d; for a 23 the surface resistance 15 we 11 represented by 8

$$
R_{s}=R_{0}\left(1+1.157 a^{-0.276}\right)
$$

where

$$
R_{\infty}=\left[\sqrt{3} \pi\left(\mu_{0} / 4 \pi\right)^{2}(\rho R) \omega^{2}\right]^{1 / 3}
$$

We note that $(\rho R)$ 1s a property of the material, independent of purity, temperature or Erequency; for $c u(\rho \ell)=6.6 \times 10^{-16} \mathrm{D}-\mathrm{m}^{2}$. On the other hand, $a$ is temperature and 1mpurity dependent through the $\left(p^{-3}\right)$ term. It follows that $R_{\infty}$ 1s temperature and impurity independent.

The colld curve in F18. 2 is the expected value of $R_{\text {a }}$ as calculated from Egs. (3-5) using the value RRR $=220$ as provided by the anufacturer. 1,9 This disagrees with the data which can be best fit by the dashed curve which corresponds to RRR $=24$. Thls difference mey be due to surface conditions or lattice defects introduced when manufacturing the cavity.

Magnetoresistance: To measure the magnetoreslatance the cavity was placed 
In the bore of a euperconducting solenold, 10 imereed in IIquid helius at 4.4 I. The average agnetfc f1eld at the cavity aurface was raleed from 0 to 5.8 Tesle In $0.53 \mathrm{~T}$ Increants. In this serfes of sesoursente we were nore Intereated in changes in Q than In lts absolute value. Thu we saeaurad the pouner reflection coefflclent $T^{2}$ of the undercoupled cavity with 30 db directional coupler.

The resonance reflection coeffletent, couplins $\rho_{\text {, and axtermal and }}$ unloaded quelity factors $Q_{\mathrm{E}}$ and $Q_{0}$ ere related as follows

$$
\rho=Q_{0} / Q_{E} \quad r^{2}=\left|\frac{1-\rho}{1+\rho}\right|^{2}
$$

For f1xed $Q_{E}$ the changes in theee quantit1es ares

$$
\frac{\Delta Q_{0}}{Q_{0}}=\frac{\Delta \rho}{\rho}=\frac{\Delta\left(\Gamma^{2}\right)}{\Gamma\left(1-\Gamma^{2}\right)}
$$

For a given value of $\left(\Delta Q_{0} / Q_{0}\right)$ the change $\Delta \Gamma^{2}$ in the reflection coeffictent $1 \mathrm{~s}$ maximized for $\Gamma^{2}=1 / 3$. We epproximated this condition for the modes tested. The coupling loop position was held fixed during the measurements.

Date for the $T M_{010}, \mathrm{TE}_{112}$ and $T E_{113}$ modes are shown in $\mathrm{F}_{18}$. 3. The fractional change in $R_{s}$, approximately the negative of the fractional change In $Q$, is plotted as a function of $B$. We first note that $\Delta R_{s} / R_{s}$ for the $T M_{010}$ is much swaller than for the $T E_{112}$ and $T E_{113}$ modes. This is expected because the $M_{010}$ curzent flow is predominantly parallel to the magnetic fleld, and longltudinal magnetoresistance is, in general, oraller than transverse magnetoresistance. The calculated fraction of resistive disolpation due to the transverse and longltudinal currents is given in Table 1 . Secondly, we observe that at high fields $\mathrm{AR}_{\text {a }}$ is proportionel to $\mathrm{B}^{2}$. This is In contrast to DC megnetoresiatance which for polycryataline $\mathrm{Cu}$ in this fleld range is nearly 11 near ${ }^{12}$ in $B$. We note, however that DC nagnetorealatance in eingle $C:$ crystals is quadratic ${ }^{12}$ in $B$. The best guadratic fit to the high fleld da:? 
(B > 2.5 T) Is show by the desbed curve is $\mathrm{FI}$. 3. We now aseme that

$$
\Delta R_{a}=\frac{I_{\|}^{2}}{I_{H}^{2}+I_{\perp}^{2}} \Delta R_{\|}+\frac{I_{I}^{2}}{I_{H}^{2}+I_{\perp}^{2}} \Delta R_{\perp}
$$

and from the date find 13

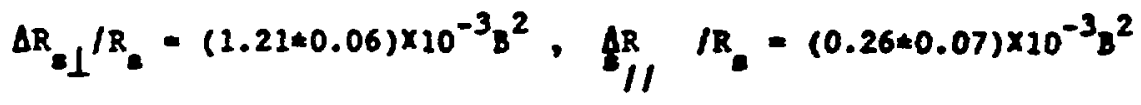

where $B$ is expressed in Tesla.

In contrast to the quedratic dependence on B, as shown In Eqs. (9), the DC magnetoresistance is Ifnear in the magnetic fleld. For our best flt value of $R R R=24$ the bulk magnetoresletance at $B=5.8 T$ s $11,14 \Delta p_{\perp} / p=0.39$ and $\Delta p_{/} / P=0.1$ to 0.3 depending on oxygen content. At the same fleld value, the measured data show a change in surface resistance of only a few percent. That the effect is so small can be attributed to the small skin depth asoociated with the RF surface current. 15

Size Efiects: Of epecial interest is the behevior of $\Delta R_{\mathrm{a}} / R_{\text {s }}$ at amell magnetic fields. The data indicate a reduction in realstivity of elmilar magnitude fo: $a 11$ three modes. By subtracting the quadratic fit from the $\Delta R_{g} / R_{s}$ data, we obtain the lower curve abow In FIg. 3; the data are sumartzed in F1g. 4. Simliar effects are found in thin filos or wires ${ }^{16}$ when the conduction electrons are confined to smaller cyclotron orbits by the increasing magnetic field and thus ouffer fewer collisions with the wetal surface. The average cyclotron radius of anduction electron is

$$
r_{c}=k_{F}\left(\zeta_{C} / e B\right)=\left(6.4 \times 10^{-6}\right)(1 \operatorname{Tes} 1 / B)=
$$

where we used $k_{F} \approx 10^{8} \mathrm{~cm}^{-1}$. Thls is to be compered with the wean free path, which for our best flt value of $R R R=24$ Is $2=1.1$ por and with the clasefcal skin depth at $1.2 \mathrm{GHz}$ wich is $\delta=0.7 \mathrm{~mm}$.

The initial decrease in conductivity appears to eaturate at $B \sim 2-3 \mathrm{~T}$ as 
oeen In F15. 4. At th1e field velue the cyelotron radius to of the ane order as the man free path and ekIn depth. Thle is consiatent with the aseuption that the angetic fleld decrease the rate of collislone with the ourface and that the seaultant Increase In conductivity is due to the finite olse of the If conduction layer. It should be possible to obtain a quantitative description of thls effect. 17

It 13 - pleasure to acknowledge the contlnued support of the B1gh Energy Physice and AGS programs at Brookheven National Laboratory. We thank Prof. T. G. Castner for many valuable discusstons and Messs. P. Borrelld and H. H1ldebrand for Important technical contributions. Th1s work was oupported by the D.S. Department of Energy.

\section{References}

1. Hitach1 Itd: Alloy number Cl01000FE-HIT oxygen free electronfc copper.

2. S. De Panf111s et 2., Phys. Rev. Lett. 59, 839 (1987).

3. Conceptual Design of the Superconducting Super Collider, SSC Central Design Group clo IBL, Berkeley, CA (1986).

4. Proprletary copper electropolishing concentrate produced by Electro-glo Corporation, ChIcago, III.

5. See for Inetance J. C. Slater, Microwave Electronice, D. Van Noctrand, Princeton (1950).

6. J. D. Jackson, Classical Electrodynamics, 2nd ed., Wlley, Hew York (1975) Pp. 298, 339.

7. B. Bahn and B. J. Balama, BNL Report AADD-129, Januery 1967 (unpublished).

B. A. B. Plppard, Proc. Roy. Soc. (London) A191, 385 (1947). 
9. Dur cin meaurcent of an annealed wre eawple obtained from this copper gave RRR - 180 .

10. J. A. Bamberger et 1. ., Adv. Cryog. Eng. 13, 132 (1967).

11. Selected Cryogenle Data Motebook, Brookhaved National Laboratory Report BNL 10200-R, Vol. I (2980).

12. J. I. Olsen, Electron tranoport in wetale". Intersclance, How Iork 1967, p. 74.

13. The values of $\Delta R_{1} / R_{0}$ and $\Delta R_{1 /} / R_{0}$ obtalned from the $M_{010}$ and $T E_{112} p a 15$ are in agreement with those from the $\mathrm{IH}_{010}$ and $\mathrm{TE}_{113}$ pair.

14. R. L. Dolecek et 2., Phys. Rev. 119, 1501 (1960).

15. In the extreme anomalous skin effect limit one expects $R_{0}$ to be Independent of $B$.

16. R. G. Chambers, Proc. Roy. Soc. (London) A202, 378 (1950), E. H. Sondheimer, Advances in Physics, 1, 1, (1952).

17. The observed effects for thin wires are considerably larger than found in th1s investigation; see also ref. 12. 
Table 1

Propert1es of Cevits Modes

\begin{tabular}{lllll} 
Hode & $f(\mathrm{GHz})$ & $A$ & $Q\left(4^{\circ} \mathrm{K}\right)$ & $I_{1}^{2} /\left(I_{1}^{2}+I^{2}\right)$ \\
\hline $\mathrm{II}_{010}$ & 1.415 & 378 & $1.13 \times 10^{5}$ & 0.16 \\
$\mathrm{IE}_{112}$ & 1.298 & 343 & $1.15 \times 10^{5}$ & 0.73 \\
$\mathrm{TE}_{113}$ & 1.523 & 473 & $1.15 \times 10^{5}$ & 0.58
\end{tabular}




\section{Firure Captions}

Fipure 1 Scheantic diegram of the epparatua. (E) Measureantent Q-ralue by transaission, (b) Measureaent of $A Q / Q$ by reflection.

Firure 2 Surface realstance in Obns ve. teoperature, normalised to f=1.249 CHz. The curves are the predictlon of the theory of the enomalous skin effect for two different values of RRR. The errors of the deta polats are of the order of the syabola used in the graph.

Flgure 3 The fractional change in surface resistance as a function of magnetic fleld. Dashed curve: quadratic fit to data for B > 2.5 I shffted to tive origin at $B=0$; dotted curve: resfduals obtalned by subtracting tire quadratic effect from the data. Data are shown for three modes. The errors are typlcaliy $\left|\delta\left(\Delta R_{s} / R_{s}\right)\right| S 10^{-3}$.

Figure 4 The residuals for 11 three modes are of the ame order and are attributed to alze effect as discussed in the text. 

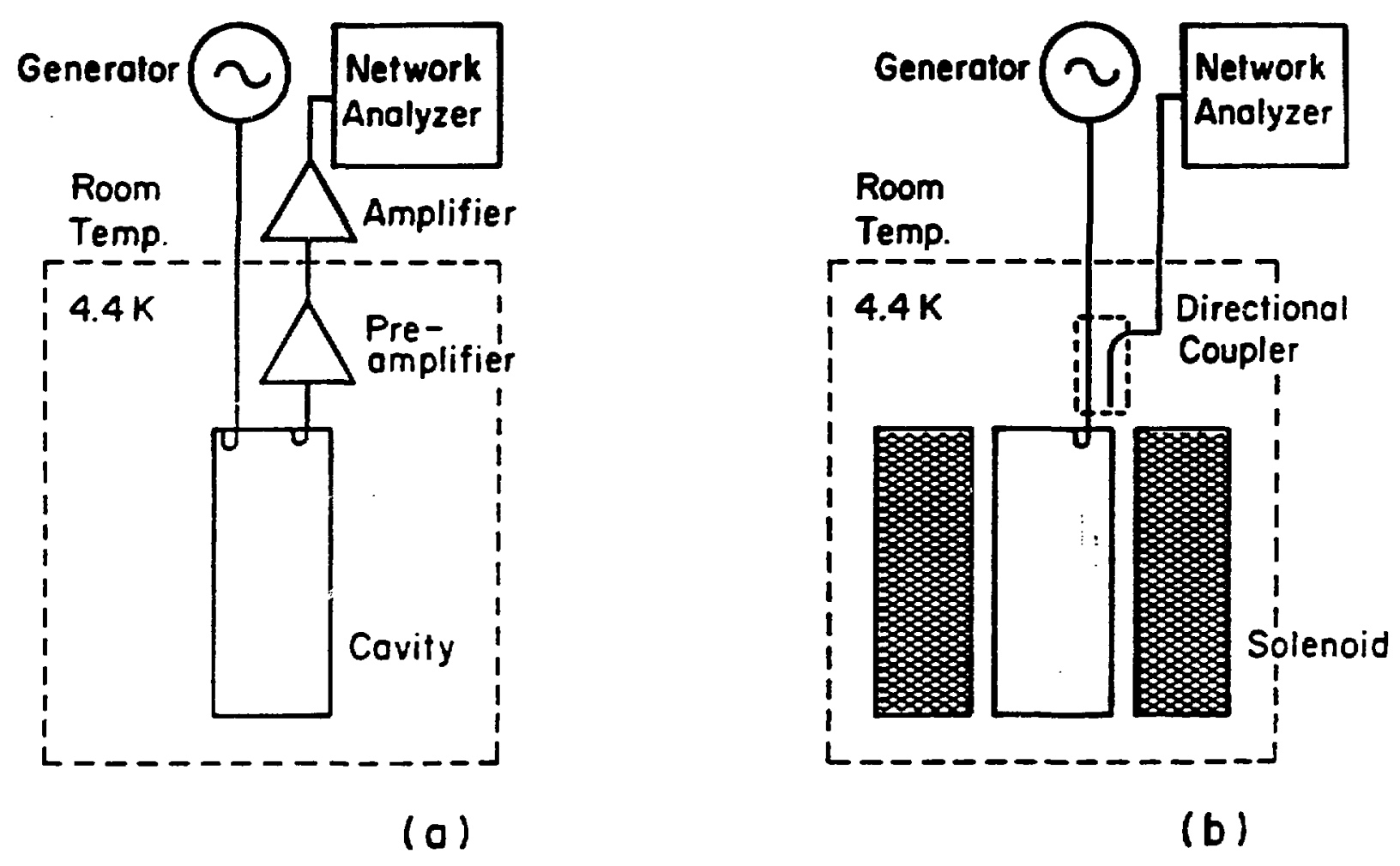

FIg. 1 


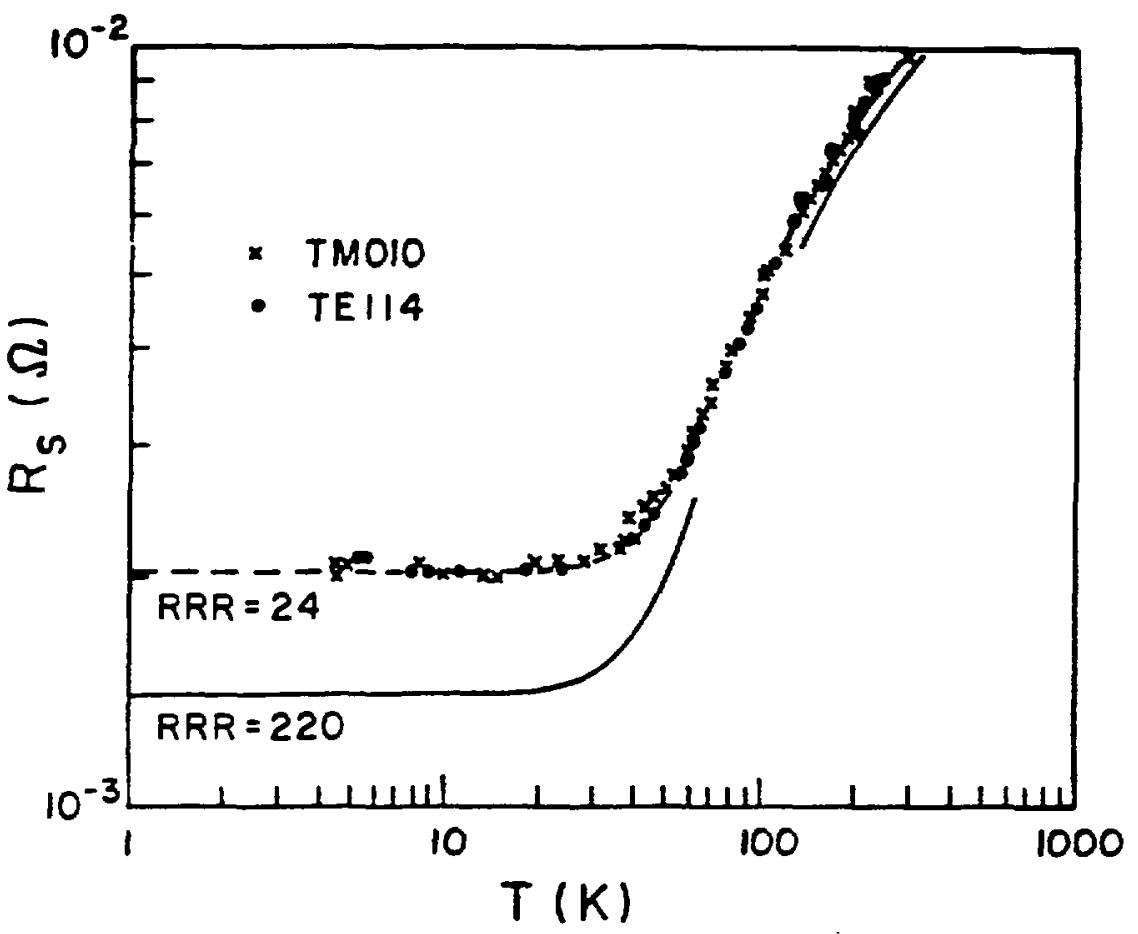

F1g. 2 

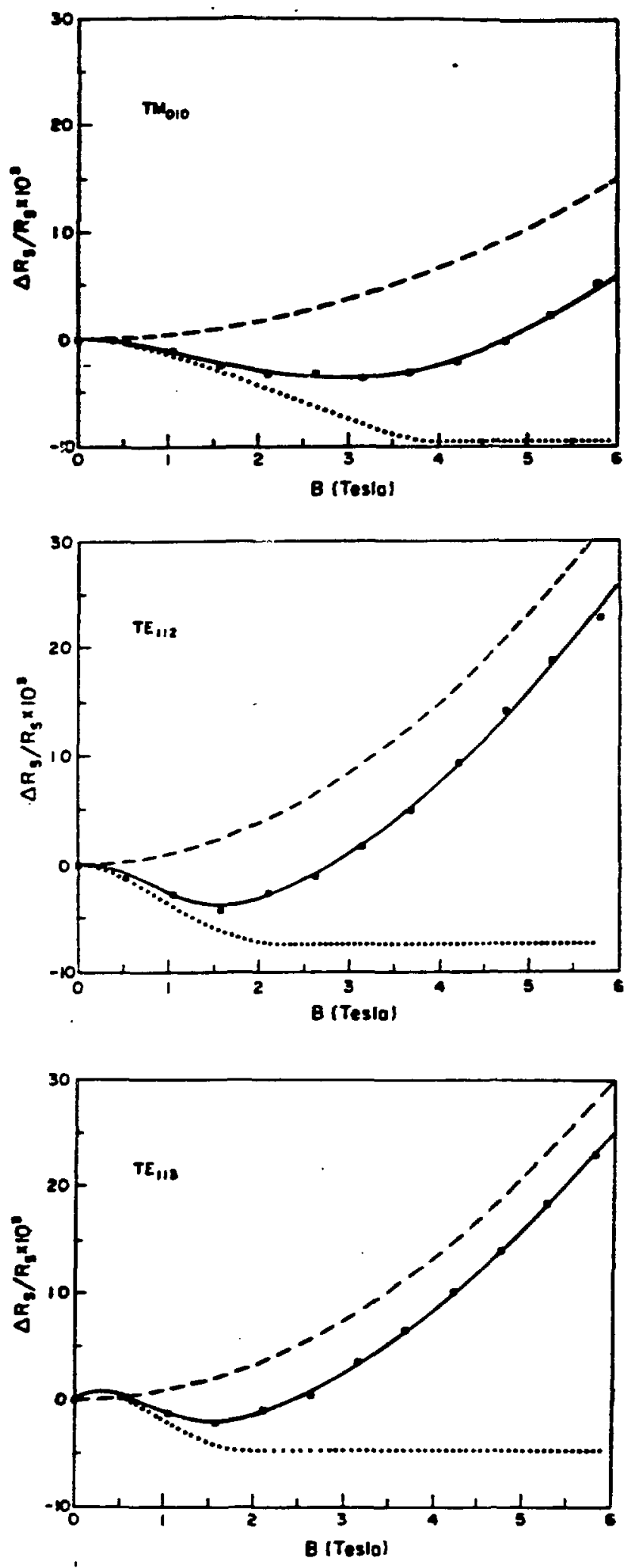

Fig. 3 


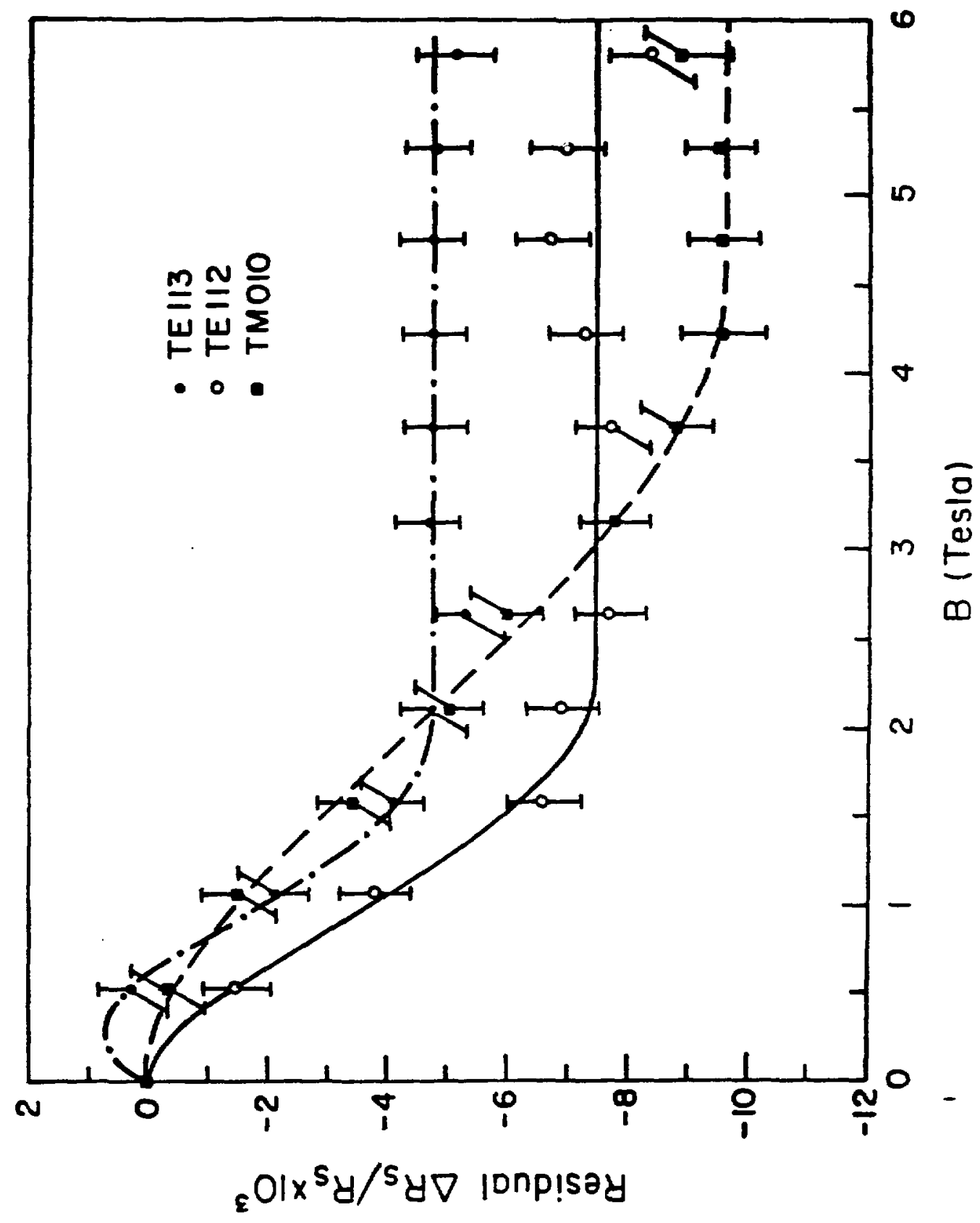

